\title{
PENCARIAN SPBU TERDEKAT DAN PENENTUAN JARAK TERPENDEK MENGGUNAKAN ALGORITMA DIJKSTRA (STUDI KASUS DI KABUPATEN JEMBER)
}

\author{
Windi Eka Yulia R., Dwiretno Istiadi, Abdul Roqib \\ Program Studi Sistem Informasi \\ Universitas Jember \\ e-mail:windi.ilkom@unej.ac.id
}

\begin{abstract}
Abstrak - Stasiun Pengisian Bahan Bakar (SPBU) untuk umum merupakan prasarana yang disediakan PT Pertamina untuk memenuhi kebutuhan bahan bakar. Prasarana ini cukup penting di semua kota, salah satunya Jember. Akses informasi letak dan fasilitas SPBU di Kabupaten ini masih sangat sulit didapatkan. Penelitian ini membahas tentang pemetaan lokasi, pencarian lokasi, dan penentuan jalur terpendek untuk mencapai lokasi SPBU tersebut. Pencarian SPBU terdekat pada penelitian ini menggunakan algoritma Dijkstra. Hasil pengambilan data didapatkan 33 SPBU yang menjual premium dan bio solar di Kabupaten Jember. Pencarian SPBU terdekat dipengaruhi oleh kriteria, cost, dan reverse _cost. Dimana untuk jalan satu arah diberikan nilai reverse _cost sebesar 1000000, sehingga jalan ini tidak akan pernah dipilih. Algoritma dijkstra sangat sesuai dan mudah digunakan pada studi kasus di penelitian ini. Penerapan algoritma dijkstra telah merekomendasikan jalur terpendek jarak tempuh guna memberikan efisiensi penggunaan bahan bakar kendaraan bermotor.
\end{abstract}

Kata Kunci : SPBU, Algoritma Dijkstra dan jalur terpendek

\begin{abstract}
Fuel Filling Station (Gas Station) to the public is an infrastructure provided by PT Pertamina. This infrastructure is quite important in all cities, one of which is Jember. Access to information and facilities layout stations in this district is still very difficult to obtain. This study discusses the mapping of the location, location, and the determination of the shortest path to reach the location of the gas station. Search nearby gas stations in this study using the Djiktra's algorthm . The results of the data collection obtained 33 gas stations that sell gasoline and bio- diesel in Jember. The shortest path location is dependent on criteria , cost, and reverse_cost. To identification of one way by providing high value to reverse_cost parameter of 1000000 , so this road will never be selected. Dijkstra's algorithm is very suitable and easy to use on a case study in this research. Implementation of dijkstra's algorithm has recommended the shortest path in order to provide fuel efficiency of motor vehicles.
\end{abstract}

Keywords : Gas Station, Djiktsr's Algorith, and shortest path

\section{PENDAHULUAN}

Kabupaten Jember merupakan salah satu kabupaten yang berada di Jawa Timur yang memiliki peningkatan perkembangan pembangunan yang sangat pesat [1]. Salah satunya adalah pembangunan infrastruktur stasiun pengisian bahan bakar umum (SPBU). Peran dari SPBU tersebut tidak kalah penting fungsinya seperti infrastruktur penting lainnya yang ada di Kabupaten Jember. Keberadaan SPBU sangat penting karena dapat melayani masyarakat dalam memenuhi kebutuhan bahan bakar kendaraan bermotor.

Kabupaten Jember merupakan salah satu destinasi kota yang banyak objek wisatanya [2], sehingga tidak sedikit para wisatawan dari luar kota berdatangan dengan tujuan berwisata. Kota Jember juga merupakan akses utama jalur mudik karena Kabupaten Jember merupakan salah satu pusat regional di kawasan tapal kuda, sehingga banyak pengendara kendaraan bermotor yang dari luar kota bepergian ke kota Jember baik untuk berkunjung ataupun berwisata. Di luar kota pengendara biasanya tidak begitu mengetahui letak SPBU, sehingga mereka kesulitan dalam menentukan harus ke mana dan melewati jalur mana yang lebih dekat untuk menuju SPBU.

Pada [2] dijelaskan bahwa sistem informasi geografis berbasis web dapat mempermudah pengguna mengakses informasi lokasi SPBU dimana saja dan kapan saja serta dapat membantu pengguna dalam menentukan letak 
SPBU baru yang strategis . Rute terpendek juga pernah menjadi konsen penelitian Sofyan Arifianto [4]. Pada penelitian ini diaplikasikan penentuan rute terpendek pada jaringan multi moda transportasi umum menggunakan algoritma dijkstra. Algoritma dijkstra dianggap cocok karena mudah digunakan oleh user dalam penggunaannya hanya dengan menentukan titik awal dan titik tujuan.

Berdasarkan referensi penelitian yang telah ada dapat diketahui bahwa algoritma dijkstra sesuai untuk pencarian jarak terpendek. Pada penelitian ini, akan diterapkan algoritma dijkstra untuk mencarian SPBU terdekat dan penentuan jarak terpendek di Kabupaten Jember . Hasil dari penelitian ini diharapkan dapat memberikan informasi letak SPBU dan merekomendasikan jalur terpendek jarak tempuh guna memberikan efisiensi penggunaan bahan bakar kendaraan bermotor.

\section{TINJAUAN PUSTAKA}

\section{Jalur Terpendek (Shortest Path Problem)}

Proses penghitungan rute terpendek adalah proses mencari jarak terpendek atau biaya terkecil suatu rute dari node awal ke node tujuan dalam sebuah jaringan. Pada proses penghitungan rute terpendek terdapat dua macam proses yaitu proses pemberian label dan proses pemeriksaan node. Metode pemberian label adalah metode untuk memberikan identifikasi pada setiap node dalam jaringan. Pada sebagian besar algoritma penghitungan rute terpendek, terdapat 3 label informasi yang dikelola untuk setiap node i pada proses pemberian label yaitu: label jarak d(i), parent node $\mathrm{p}(\mathrm{I})$, dan status node $\mathrm{S}(\mathrm{i})$ [5].

Algoritma yang dapat digunakan untuk mencari jalur terpendek telah banyak diteliti. Beberapa algoritma yang dapat digunakan untuk menyelesaikan penentuan jalur terpendek adalah dijkstra's algorithm, bell bellmanford's algorithm, a* search algorithm, dan floyd-warshall algorithm [6].

\section{Algoritma Dijkstra}

Algoritma dijkstra merupakan salah satu bentuk algoritma greedy. Algoritma ini termasuk algoritma pencarian graf yang digunakan untuk menyelesaikan masalah lintasan terpendek dengan satu sumber pada sebuah graf yang tidak memiliki cost sisi negatif, dan menghasilkan sebuah pohon lintasan terpendek. Algoritma ini sering digunakan pada routing [5].

Algoritma dijkstra menggunakan adjacent list untuk merepresentasikan sebuah jaringan. Secara garis besar algortima dijkstra membagi semua node menjadi dua, kemudian dimasukkan ke dalam tabel yang berbeda, yaitu tabel permanen dan tabel temporal. Tabel permanen berisi node awal dan node-node yang telah melalui proses pemeriksaan dan labelnya telah diubah dari temporal menjadi permanen. Tabel temporal berisi node-node yang berhubungan dengan node pada tabel permanen.

\section{METODOLOGI ATAU TEORI}

Penelitian ini dimulai dari pengumpulan data dan pemetaan lokasi SPBU di Kabupaten Jember . Data lain yang dibutuhkan adalah data jalan, persimpagan, dan info jalur satu arah. Data tersebut akan digunakan untuk penggambaran peta lokasi SPBU. Pencarian data yang dibutuhkan sebagian besar adalah data spatial, sehingga dibutuhkan GPS, metode tracking, dan wawancara kepada pemilik/karyawan SPBU. Data jalan di Indonesia yang didapat dari google dapat dilihat pada gambar 1. Data tersebut akan dilakukan proses intersection dengan data batas wilayah Kabupaten Jember yang ada di gambar 2. Hasil intersection dari kedua data adalah data jalan yang ada di Kabupaten Jember, dapat dilihat pada gambar 3 .

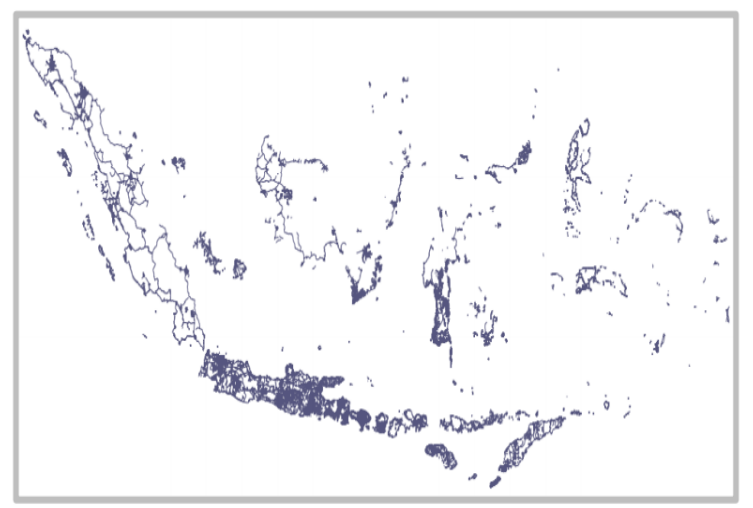

Gambar 1. Data jalan di Indonesia 


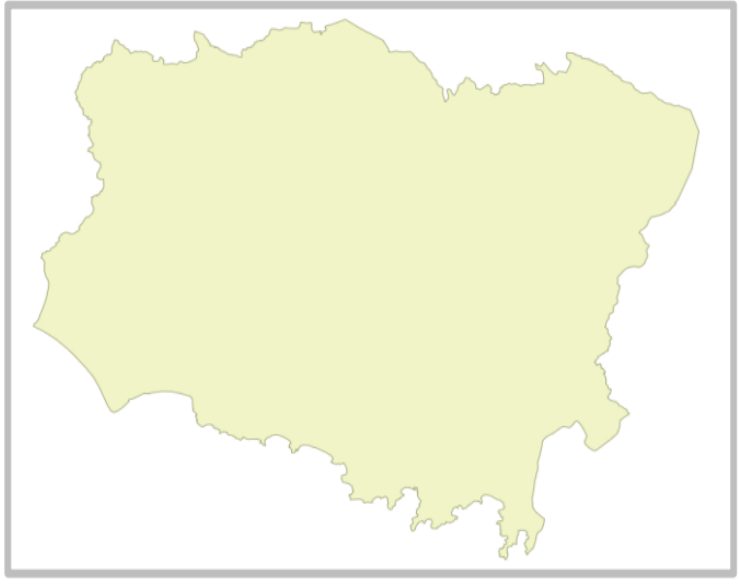

Gambar 2. Batas wilayah Kabupaten Jember

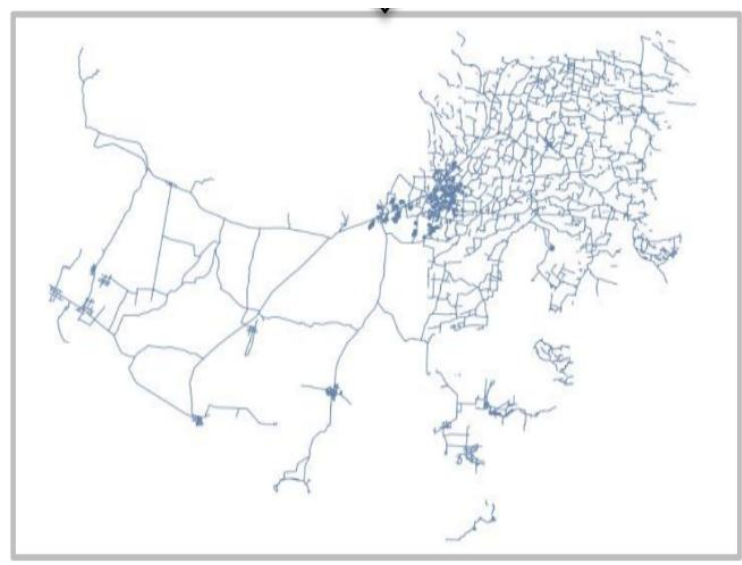

Gambar 3. Data jalan di Kabupaten Jember

Data spatial yang didapat akan digunakan untuk proses intersection dengan data jalan yang ada di Indonesia. Hasil proses tersebut akan didapat data jalan yang ada di Kabupaten Jember saja. Data atribut yang berupa nilai kriteria, cost, dan reverse _cost akan digunakan dalam perhitugan algoritma Dijkstra untuk mendapatkan jalur terpendek. Detail proses penentuan jalur terpendek menuju lokasi SPBU menggunakan algoritma dijkstra dapat dilihat pada gambar 4 .

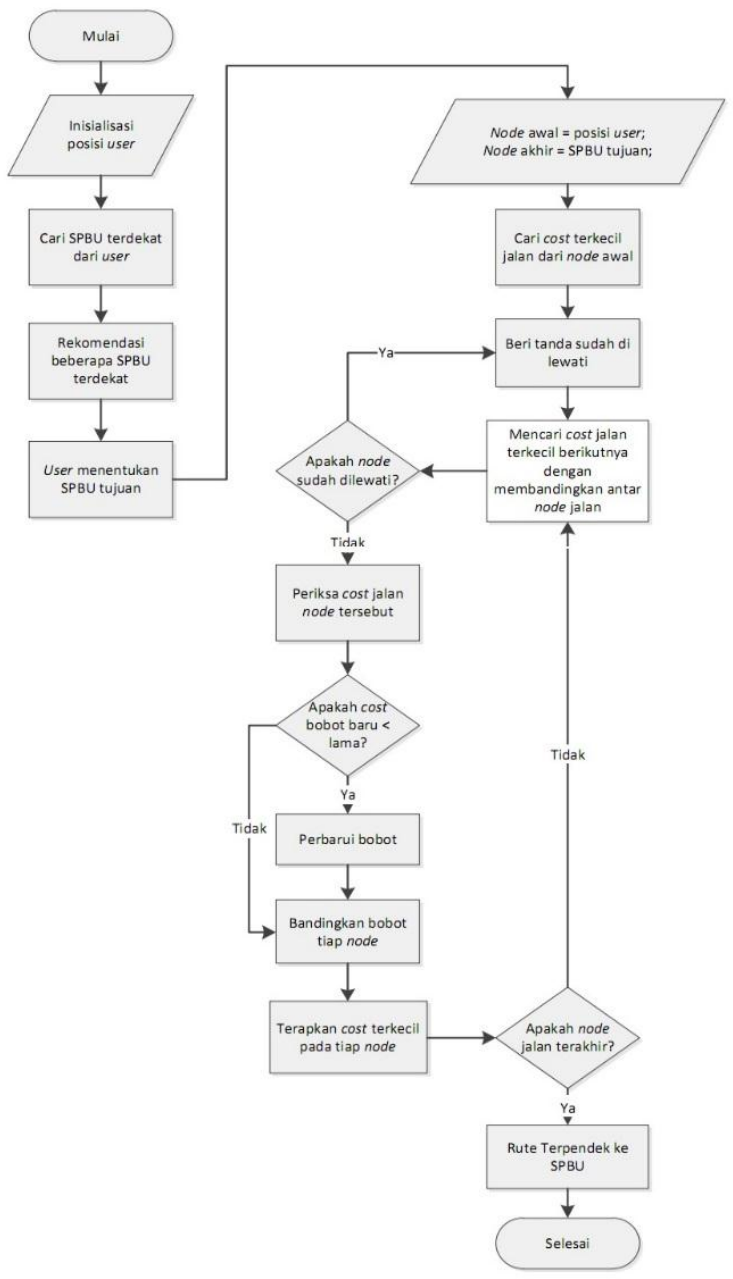

Gambar 4. Diagram penentuan jalur terpendek SPBU

\section{HASIL DAN PEMBAHASAN}

Pencarian SPBU terdekat pada penelitian ini dimulai dengan menghitung jarak user ke masing-masing SPBU. Perhitungan jarak dilakukan oleh sistem dengan memilih posisi user pada peta. Perhitungan jarak ini akan menghasilkan rekomendasi SPBU terdekat dari posisi user. Proses ini membutuhkan beberapa parameter, yaitu parameter geometry awal dalam hal ini adalah posisi user dan geometry akhir dalam hal ini adalah posisi SPBU terdekat. Parameter tersebut akan dihitung untuk mendapatkan perbandingan jarak dengan menggunakan rumus Haversine formula pada persamaan 1 .

$d=2 r x \arcsin \left(\sqrt{\sin ^{2}\left(\frac{\varphi 2-\varphi 1}{2}\right)+\cos \varphi_{1} \cos \varphi_{2} \sin ^{2}\left(\frac{\lambda 2-\lambda 1}{2}\right)}\right)$ 
Perhitungan SPBU terdekat pada penelitian ini dapat diberikan 1 contoh kasus detail. Langkah pertama adalah penentuan posisi user dan posisi SPBU terdekat yang dapat dilihat pada gambar 5 .

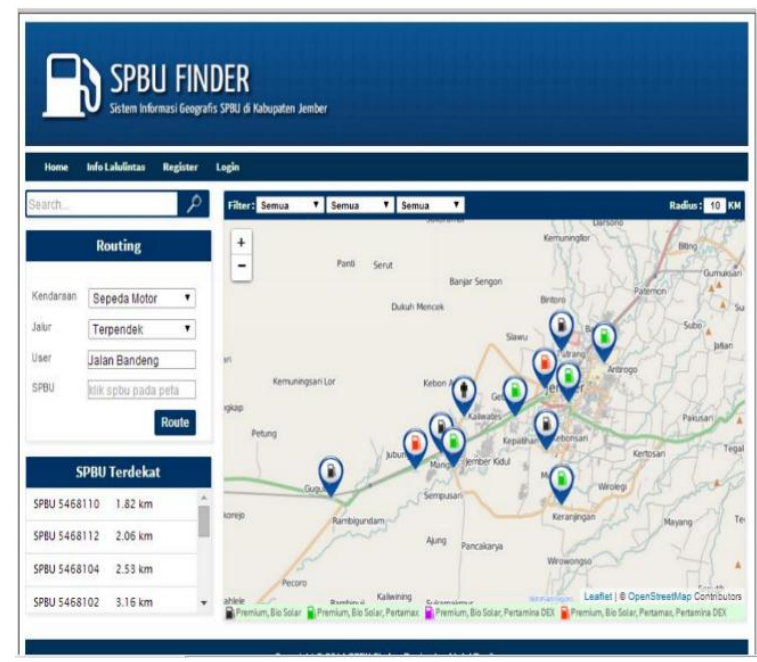

Gambar 5. Posisi user dan SPBU terdekat

Langkah kedua posisi geometry user dan SPBU dibandingkan unntuk mendapat jaraknya. Hasil perbandingan jarak dapat dilihat pada tabel 1. Dari hasil perbandingan tersebut akan dilakukan perhitungan jalur terpendek. Perhitungan ini dilakukan dengan meenghitung panjang pada masing-masing jalan. Pada penelitian ini, setiap persimpangan jalan yang ada adalah vertex. Parameter yang harus diperhatikan adalah jenis kendaraan apa yang digunakan oleh user dan arah jalur pada jalan tersebut. Jenis kendaraan diperlukan untuk mencari jalan terdekat yang sesuai dengan kendaraan user. Beberapa jalan hanya bisa dilalui oleh sepeda motor, sehingga jalan tersebut tidak akan dipilih ketika user menggunakan mobil.

Langkah berikutnya adalah perhitungan jalur terpendek dengan menggunakan algoritma Dijkstra . Perhitungan ini dapat dilakukan dengan representasi graph. Jalan antara user dengan SPBU digambarkan dengan edge, sedangkan setiap persimpangan akan digambarkan dengan vertex.
Tabel 1. Hasil perbandingan jarak geometry

\begin{tabular}{|c|c|c|c|c|c|c|c|}
\hline No & Vyy-1 & SPBU & OOVCITUEF & 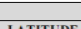 & ER & JARAK (M) & $\begin{array}{l}\text { JARAK } \\
\text { JaRAD }\end{array}$ \\
\hline & SPBU & & NGIITOE & & & & \\
\hline 1 & 5468110 & -8.19192412 & 113.646492 & -8.178911 & 113.6566544 & 1830.935529 & 1.83 \\
\hline 2 & $\begin{array}{l}\text { SPBU } \\
5468112\end{array}$ & -8.196887748 & 113.6518723 & -8.178911 & 113.6566544 & 2069.3060022 & 2.069 \\
\hline 3 & $\begin{array}{l}\text { SPBU } \\
5468104\end{array}$ & -8.17896979 & 113.6795784 & -8.178911 & 113.6566544 & 2525.93515 & 2.520 \\
\hline 4 & $\begin{array}{l}\text { SPBU } \\
5468102\end{array}$ & -8.197468386 & 113.6348375 & -8.178911 & 113.6566544 & 3169.573532 & 3.17 \\
\hline 5 & $\begin{array}{l}\text { SPBU } \\
5468123\end{array}$ & -8.1689977337 & 113.6931183 & -8.178911 & 113.6566544 & 4167.297025 & 4.16. \\
\hline 6 & $\begin{array}{l}\text { SPBU } \\
54681111\end{array}$ & -8.19071393 & 113.6939041 & -8.178911 & 113.6566544 & 4309.558719 & 4.3 \\
\hline 7 & $\begin{array}{l}\text { SPBU } \\
5468125\end{array}$ & -8.173862263 & 113.7036793 & -8.178911 & 113,6566544 & 5211.965386 & 5.212 \\
\hline 8 & $\begin{array}{l}\text { SPBU } \\
54681113\end{array}$ & -8.155831445 & 113.7004982 & -8.178911 & 113,6566544 & 5471.830694 & 5.472 \\
\hline & $\begin{array}{l}\text { SPBU } \\
5468119\end{array}$ & -8.210197089 & 113.700735 & -8.178911 & 113,6566544 & 5976.559456 & 5.977 \\
\hline
\end{tabular}

Notasi graph hasil representasi pencarian jalur terpendek SPBU dapat dilihat pada gambar 6 .

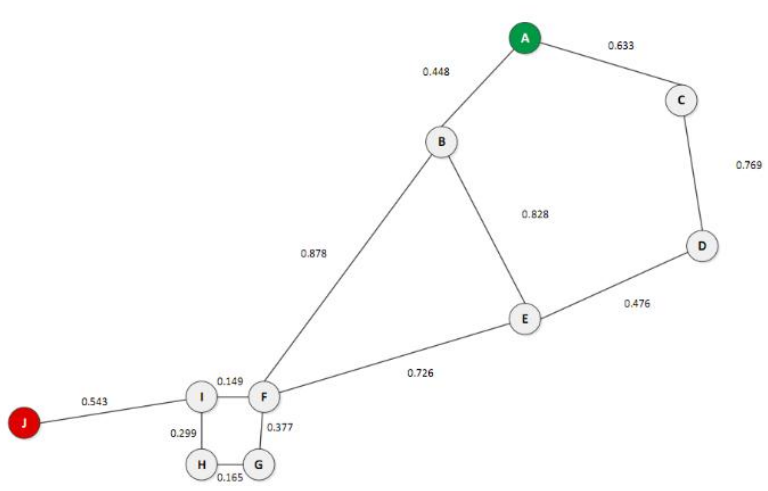

Gambar 6. Notasi graph pencarian jalur terdekat

Penentuan jalur terpendek pada gambar 6 dengan menggunakan algoritma Dijkstra menghasilkan rute terpendek $\mathrm{A} \rightarrow \mathrm{B} \rightarrow \mathrm{F} \rightarrow \mathrm{I} \rightarrow \mathrm{J}$. Perhitungan penyelesaiannya dapat dilihat pada tabel 2.

Tabel 2. Hasil perhitungan algoritma Dijkstra

\begin{tabular}{cccc}
\hline No. & Vertex Sumber & \multicolumn{2}{c}{ Jarak dengan Vertex Lain } \\
\hline 1 & $\mathrm{~A}$ & $\mathrm{~A} \rightarrow \mathrm{B}$ & 0.448 \\
\cline { 3 - 4 } & & $\mathrm{A} \rightarrow \mathrm{C}$ & 0.633 \\
\hline 2 & $\mathrm{~B}$ & $\mathrm{~B} \rightarrow \mathrm{E}$ & $0.448+0.828=1.276$ \\
\cline { 3 - 4 } & & $\mathrm{B} \rightarrow \mathrm{F}$ & $0.448+0.878=1.326$ \\
\hline 3 & $\mathrm{C}$ & $\mathrm{C} \rightarrow \mathrm{D}$ & $0.633+0.769=1.402$ \\
\hline 4 & $\mathrm{D}$ & $\mathrm{D} \rightarrow \mathrm{E}$ & $1.402+0.476=1.878$ \\
\hline 5 & $\mathrm{E}$ & $\mathrm{E} \rightarrow \mathrm{F}$ & $1.276+0.726=2.002$ \\
\hline 6 & $\mathrm{~F}$ & $\mathrm{~F} \rightarrow \mathrm{G}$ & $1.326+0.377=1.703$ \\
\cline { 3 - 4 } & & $\mathrm{F} \rightarrow \mathrm{I}$ & $1.326+0.149=1.475$ \\
\hline 7 & $\mathrm{I}$ & $\mathrm{I} \rightarrow \mathrm{H}$ & $1.475+0.299=1.774$ \\
\cline { 3 - 4 } & & $\mathrm{I} \rightarrow \mathrm{J}$ & $1.475+0.543=2.018$ \\
\hline
\end{tabular}


Hasil perhitungan dari algoritma dijkstra telah diimplementasikan kedalam sistem pada penelitian ini. Hasil yang ditampilkan sistem dengan contoh kasus ini telah sesuai dengan perhitungan manual algoritma dijkstra. Perhitungan dari sistem dapat dilihat pada gambar 7.

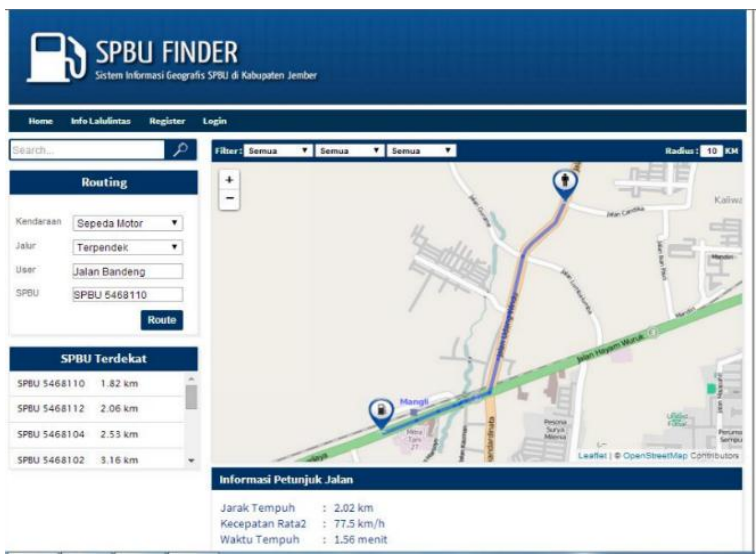

Gambar 7. Hasil perhitungan pada sistem

Untuk menguji ketepatan perhitungan dan implementasi algoritma dijkstra, penentuan jalur terpendek juga dihitung dengan menggunakan software lain yaitu QuantumGIS. Hal ini dilakukan untuk melihat apakah jalur yang dihasilkan sudah benar. Dari hasil perbandingan didapatkan hasil bahwa jalur yang telah diperoleh sama dengan perhitungan QuantumGIS.

\section{KESIMPULAN}

Kesimpulan dari penelitian ini dapat dibagi menjadi beberapa yaitu :

1. Hasil pengambilan data pemetaan SPBU di Kabupaten Jember didapatkan 33 SPBU dimana semua SPBU menjual bahan bakar premium dan bio solar. Dari 33 SPBU tersebut 19 menjual pertamax, 7 menjual pertamax dex, dan 6 menjual keduanya.

2. Hasil perhitungan jarak terpendek dalam pencarian SPBU dipengaruhi oleh nilai kriteria, cost, dan reverse _cost. Sedangan nilai waktu tempuh didapat dari perhitungan jarak dibagi dengan kecepatan.

3. Identifikasi jalan satu arah dilakukan dengan memberikan nilai reverse _cost sebesar
1000000. Nilai ini diberikan agar pada saat perhitungan, jalan ini mempunyai nilai yang tinggi dibandingkan jalan lain. Sehingga jalan ini tidak akan pernah dipilih.

4. Penentuan jalan yang diambil oleh sistem juga ditentukan oleh jenis kendaraan yang digunakan oleh user. Pada penelitian ini yang diambil adalah mobil dan sepeda motor.

\section{DAFTAR PUSTAKA}

[1] Arifin, Edy Burhan. 2006. Pertumbuhan Kota Jember dan Munculnya Budaya Pandhalungan. Jakarta : Konferensi Nasional Sejarah VIII.

[2] Gusmao, Antonio, dkk. 2013. Sistem Informasi Geografis Pariwisata Berbasis Web Dan Pencarian Jalur Terpendek Dengan Algoritma Dijkstra. Jurnal EECCIS Vol. 7, No. 2.

[3] Darmawan, Artha Eka, dkk. Tanpa Tahun. Sistem Informasi Geografis Stasiun Pengisian Bahan Bakar Umum Di Kota Batam. Jurnal Fakultas Teknik Universitas Maritim Raja Ali Haji (UMRAH).

[4] Arifianto, Sofyan. 2012. Sistem Aplikasi Penentuan Rute Terpendek Pada Jaringan Multi Moda Transportasi Umum Menggunakan Algoritma Dijkstra. Tesis. Program Studi Magister Sistem Informasi Universitas Diponegoro Semarang.

[5] Purwananto, Yudhi, dkk. 2005. Implementasi Dan Analisis Algoritma Pencarian Rute Terpendek Di Kota Surabaya. Jurnal Penelitian dan Pengembangan TELEKOMUNIKASI. Vol. 10, No. 2.

[6] Sanan, dkk. 2013. Shortest Path Algorithm. International Journal of Application or Innovation in Engineering \& Management (IJAIEM). Volume 2, Issue 7.

\section{Biodata Penulis}

Windi Eka Yulia Retnani, S.Kom.,MT., Staff Pengajar di Universitas Jember. Lahir di Nganjuk pada tanggal 5 Maret 1984. Pendidikan S1 di jurusan Ilmu Komputer Universitas Brawijaya. Pendidikan S2 di jurusan Rekayasa Perangkat Lunak Institut Teknologi Bandung. 